\title{
The dimerization interface in VraR is essential for induction of the cell wall stress response in Staphylococcus aureus: a potential druggable target
}

\author{
Ghazal Tajbakhsh and Dasantila Golemi-Kotra*
}

\begin{abstract}
Background: Staphylococcus aureus remains a medical challenge in the treatment of bacterial infections. It has acquired resistance to commonly used antibiotics, and to those considered to be the last weapons in treating staphylococcal infections, such as vancomycin. Studies have revealed that $S$. aureus is capable of mounting a rapid response to antibiotics that target cell wall peptidoglycan biosynthesis, such as $\beta$-lactams and vancomycin. The two-component system VraSR has been linked to the coordination of this response. VraS is a histidine kinase that undergoes autophosphorylation in the presence of signals elicited upon cell wall damage and it then transfers its phosphoryl group to VraR. VraR is a response regulator protein that functions as a transcription factor. Phosphorylation of VraR leads to its dimerization, which is required for optimum binding to its target promoters. Two-component systems have been targeted for the development of antibacterial agents. Deletion of the vraS or vraR gene has been shown to re-sensitize $S$. aureus to $\beta$-lactams and vancomycin.

Results: In this study, we explored perturbation of the VraR phosphorylation-induced activation as a means to inhibit the VraSR-mediated signal transduction pathway. We show that dimerization of VraR is essential for the phosphorylation-induced activation of $\mathrm{VraR}$. A single point mutation in the dimerization interface of $\mathrm{VraR}$, in which Met13 was replaced by Ala, led to the inability of VraR to dimerize and to bind optimally to the target promoter. The consequences of these in vitro molecular deficiencies are equally dramatic in vivo. Complementation of a vraR deletion S. aureus strain with the vraRM13Ala mutant gene failed to induce the cell wall stress response.
\end{abstract}

Conclusions: This study highlights the potential of targeting the phosphorylation-induced dimerization of VraR to disrupt the $S$. aureus cell wall stress response and in turn to re-sensitize $S$. aureus to $\beta$-lactams and vancomycin.

Keywords: Two-component systems, VraSR, Cell wall stress stimulon, Staphylococcus aureus

\section{Background}

Two-component signaling systems (TCSs) are prevalent in bacteria $[1,2]$. They enable coupling of a diverse array of adaptive responses to environmental stimuli including antibiotic stress [1,3]. Their absence in high eukaryotic systems makes them a prime target for development of novel antimicrobial agents [4]. Signaling via TCSs is based on a conserved phosphor transfer process between a histidine kinase $(\mathrm{HK})$ and a response regulator protein

\footnotetext{
*Correspondence: dgkotra@yorku.ca

Department of Biology, York University, Toronto, ON M3J1P3, Canada
}

(RR) (Fig. 1). The output response is controlled by the $R R$, which plays the role of a phosphorylation-activated switch [5]. About $60 \%$ of all identified RRs act as transcription factors [5].

The vancomycin-resistance-associated response regulator protein, VraR, and its cognate histidine kinase, VraS, constitute a two-component system in Staphylococcus aureus (Fig. 1a) that has been shown to mediate resistance to $\beta$-lactams and vancomycin [6]. VraSR has gained attention as a potential target in encountering the antibiotic resistance in multiple antibiotic resistant $S$. aureus strains

(c) The Author(s). 2019 Open Access This article is distributed under the terms of the Creative Commons Attribution 4.0 International License (http://creativecommons.org/licenses/by/4.0/), which permits unrestricted use, distribution, and 
such as MRSA. Deletions within the vraSR operon resensitize MRSA strains to $\beta$-lactams and vancomycin [711]. The VraSR-mediated signal transduction pathway is activated by the exposure of $S$. aureus to antibiotics and gene deletions that inhibit cell wall synthesis $[6,12,13]$. Cell wall damage in $S$. aureus leads to the VraR-dependent regulation of more than 40 genes [6]. However, the precise nature of the signal(s) that turns on the VraSR-mediated signaling pathway is not known. Both $\mathrm{VraS}$ and VraR are multidomain proteins (Fig. 1a). VraS consists of an Nterminal transmembrane domain, which, in a number of histidine kinases, is involved in sensing the extracellular stimuli, and a C-terminal core domain that harbors the dimerization interface, the conserved histidine residue, and the ATP-binding domain. VraR consist of a conserved $\mathrm{N}$-terminal domain that harbors the phosphorylation site, referred to as the regulator domain (RD), and a variable C-terminal domain that interacts with DNA, referred to as the effector domain (ED) (Fig. 1a). Upon cellular stress, $\mathrm{VraS}$ is activated through an autophosphorylation event $\left(t_{1 / 2} \sim 10 \mathrm{~min}\right)[12,14]$. Subsequently, the histidine kinase transfers the phosphoryl group, almost instantaneously $\left(t_{1 / 2}\right.$ $\sim 10$ s), onto VraR [14]. Upon its phosphorylation, VraR dimerizes at the N-terminal domain. Phosphorylationinduced dimerization is shown to expand and enhance the VraR binding to its own promoter (Fig. 1b) [14-16], and, consequently, to increase the expression of the vraSR operon [17]. Higher vraR expression leads to modulation of as many as 40 genes, which ultimately constitute the $S$. aureus response to cell wall damage. The VraSR-mediated signal transduction is reset in the absence of stress through the phosphatase activity of VraS toward VraR [14].

The events that lead to the phosphorylation-induced dimerization of VraR have been elucidated by hydrogendeuterium mass spectrometry and X-ray crystallography $[16,18]$. These studies showed occurrence of structural rearrangement in the VraR regulator domain in the phosphorylated dimeric species. In particular, the crystal structure showed that these structural rearrangements ultimately are associated with the formation of a hydrophobic pocket that wraps snugly the side chain of a methionine residue, Met13, which protrudes from an $\alpha$-helix region $(\alpha 1$ helix) of the opposing protomer in the dimer complex (Fig. 2) [16]. This discovery provided a strategy for the targeting of two-component signal transduction pathways, that of inhibition of the phosphorylation-induced dimerization of RR.

VraR belongs to the NarL/FixJ family of RR, which use the helix-turn-helix motif to bind to DNA. The dimerization interface found in VraR is seen in a subset of this family of proteins, for example in Escherichia coli UhpA [19], a response regulator that regulates sugar uptake, Mycobacterium tuberculosis NarL [20], S. aureus LuxR (PDB ID 3B2N), a response regulator implicated in regulation of cell-density, Bacillus subtillis DesR [21], and Enterococcus faecium LiaR, a response regulator involved in daptomycin induced cell wall stress response [22]. The response regulator proteins that belong to the $\mathrm{OmpR} / \mathrm{PhoB}$ family of proteins, which use a winged helix-turn-helix to target DNA, implicate the $\alpha 4-\beta 5-\alpha 5$ interface for dimerization [23].

In this study, we investigated the role of Met13 in the phosphorylation-induced dimerization and binding of VraR to its own promoter. Our in vitro and in vivo studies revealed the profound effect that this single amino acid residue has on the cell-wall antibiotic stress response in $S$. aureus. In addition, they validated the significance of inhibition of the phosphorylation-induced activation of VraR in re-sensitizing $S$. aureus to $\beta$ lactams and vancomycin.

\section{Results}

\section{Characterization of the VraRM13A variant}

The VraRM13A variant was purified to homogeneity as described before [14]. To assess the impact of substitution of Met13 by Ala on the overall secondary structures and the structural integrity of VraR, we recorded the CD spectrum of the VraRM13A variant and its thermal melting, respectively, and compared these data against the wild-type protein $\mathrm{CD}$ spectrum and the thermal melting. The CD spectra of VraR and VraRM13A were similar, indicating that the substitution of Met by Ala did not have a deleterious effect on the secondary structural features of the protein (see Additional file 1: Figure S1A). This outcome was to be expected as Met-13 residue sits on an $\alpha$-helix $(\alpha 1)$ and its substitute, alanine, is a strong $\alpha$-helix former [24]. The thermal melting studies also showed that the stability of the variant protein was similar to that of the wild-type protein, inferring that the overall integrity of the protein was not affected (see Additional file 1: Figure S1B).

\section{Phosphorylation of VraRM13A}

Phosphorylation of VraR and VraRM13A by a small molecule donor such as acetyl phosphate was assessed by Phos-tag ${ }^{\mathrm{mi}}$ SDS-PAGE: the un-phosphorylated and phosphorylated protein species were separated by the SDS-PAGE as a result of the phosphorylated species mobility being slowed down by the Phostag reagent in the SDS-PAGE (Fig. 3). The protein bands, stained with coomassie blue, were quantified by ImageJ (NIH). These experiments showed that after $45 \mathrm{~min}$ of incubation the VraRM13A variant underwent about 10\% phosphorylation compared to $73 \%$ of phosphorylation measured for VraR.

\section{Oligomerization state of VraRM13A}

Earlier studies on VraR have shown that phosphorylation drives the protein, otherwise a monomer, toward 

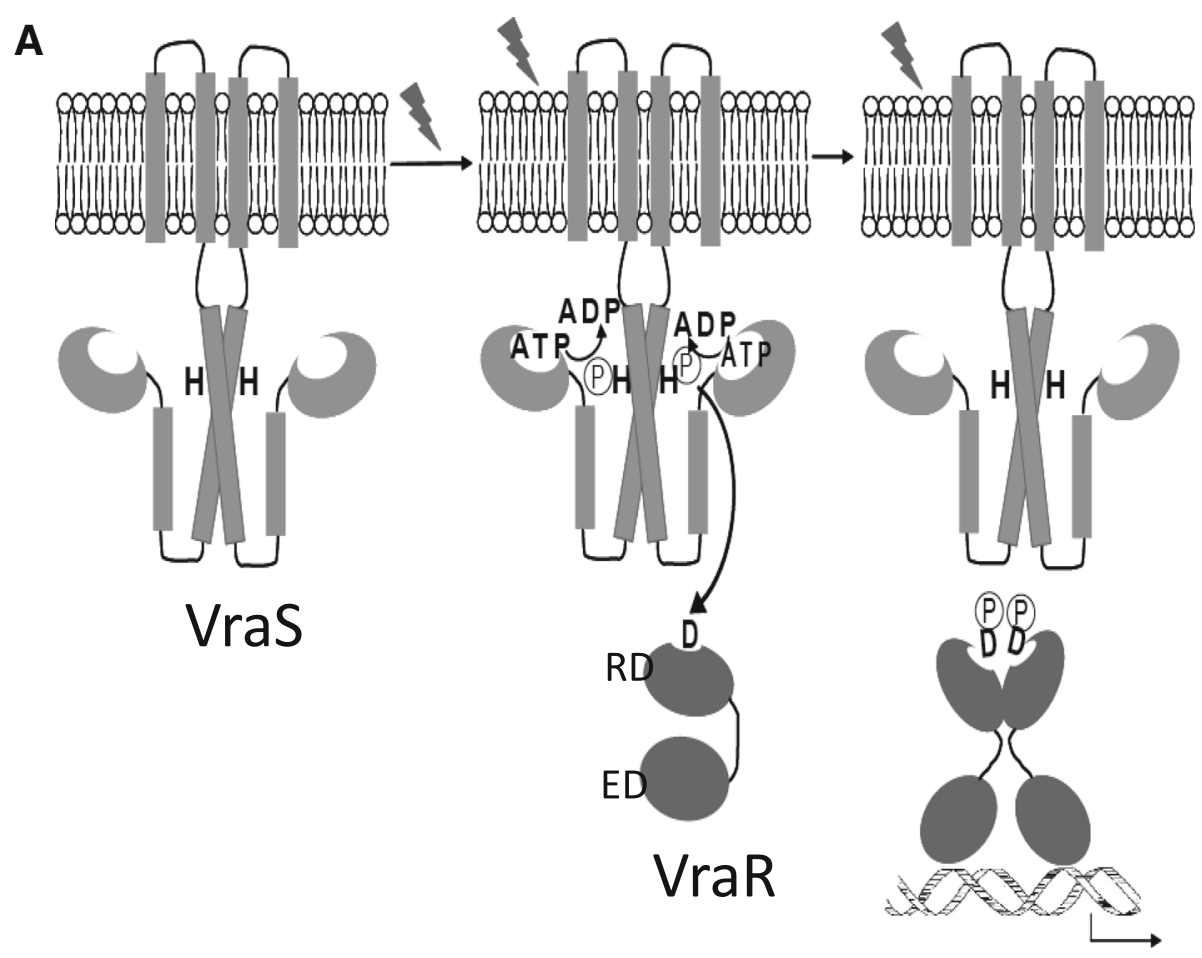

B

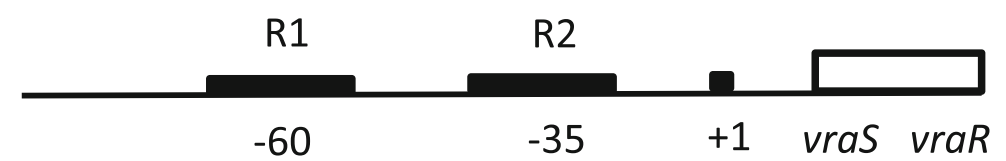

Fig. 1 Schematic views of the signal transduction pathway mediated by VraSR (a) and of the VraR-bindinding sites on the vraSR promoter (b)

dimerization [14]. The Met-13 residue was identified as one of the residues that participated intimately in dimerization (Fig. 2) [16]. Hence, reduction of the methionine side chain to that of a methyl group should have an impact on the dimerization. The native-PAGE experiments were performed to investigate the protein dimerization ability after attempting the phosphorylation. The VraRM13A variant, subjected to the phosphorylation, did not form a dimer at $10 \mu \mathrm{M}, 20 \mu \mathrm{M}$ or $30 \mu \mathrm{M}$ (or $40 \mu \mathrm{M}$, data not shown), unlike VraR (Fig. 4).

\section{Analysis of the DNA-binding activity of VraR}

To evaluate the DNA-binding activity of VraRM13A, we performed DNase I footprinting experiments. Previous studies showed that unphosphorylated VraR binds to the region -50 to -75 (namely $\mathrm{R} 1$ ) of the vras $R$ promoter $\left(\mathrm{P}_{\text {VrasR }}\right)$ while phosphorylated VraR (VraR-P) binds to an additional site of the promoter, the region -46 to -26 (namely R2), (Fig. 1b) [15]. The DNase I footprinting experiments carried out with VraRM13A showed that unphosphorylated and acetyl phosphate-treated VraRM13A bound to $\mathrm{P}_{\text {VraSR }}$ in the same way as unphosphorylated VraR
(Fig. 5); only the R1 was occupied by these proteins, not the R2 site. These results are in agreement with the outcome of the phosphorylation and oligomerization experiments, which showed that VraRM13A subjected to phosphorylation with acetyl phosphate failed to undergo quantitative phosphorylation and any measurable dimerization. We

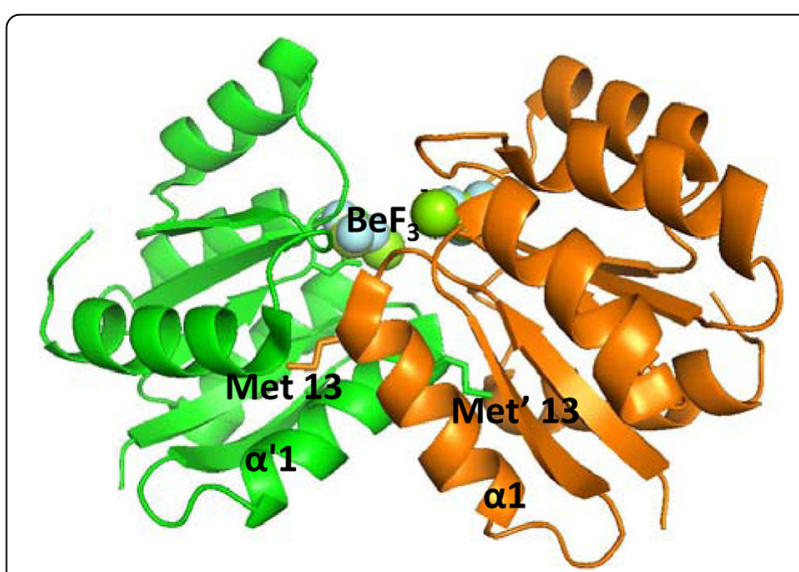

Fig. 2 The dimerization interface as resolved by X-Ray crystallography (PDB ID: 4IF4) 


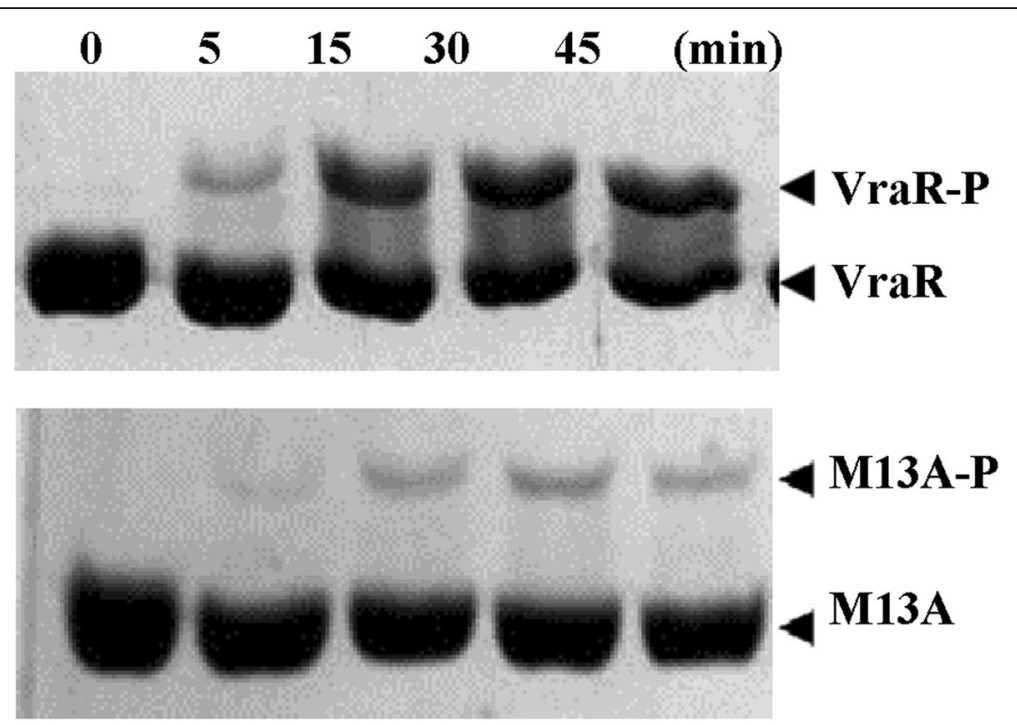

Fig. 3 Time-dependence phosphorylation of VraR and VraRM13A (M13A) by acetyl phosphate. Coomassie blue staining of the Phostag 12.5\% SDS-PAGE. The experimental conditions were as follows: VraR at $20 \mu \mathrm{M}$ concentration was incubated with $50 \mathrm{mM}$ acetyl phosphate in PB buffer at $37^{\circ} \mathrm{C}$ at different time intervals

analyzed the band intensities of three of the DNA bands observed in the VraR-protected region of $\mathrm{P}_{\text {VrasR }}$ by ImageJ, and compared the DNA binding affinity of VraRM13A to that of VraR (see Additional file 2: Figure S2). The binding isotherms show that binding of VraRM13A to the R1 site of $\mathrm{P}_{\text {VraSR }}$ was weaker than binding of VraR. We had shown earlier that the VraR DNA-binding sequence consists of two in-tandem sequences which in R1 are very close to each other, separated by one nucleotide, and as such they are likely to promote dimerization of VraR in this site [17]. The weaker DNA-binding observed for VraRM13A, in comparison to VraR, could be due to the inability of VraRM13A to engage into a dimer at the R1 site.

\section{Activation of the vraR regulon in the presence of vraRM13A}

To assess in vivo the effect of the Met13 to Ala substitution on the activity of $\mathrm{VraR}$, we generated the $\mathrm{P}_{\text {vrasR }}:$ vraRM13A construct and cloned it into the shuttle vector pMK4 [25]. The vector pMK4:: $\mathrm{P}_{\text {vrasR }}$ vraRM13A complemented the $R N 4220 \Delta v r a R$ strain well as assessed by measuring the

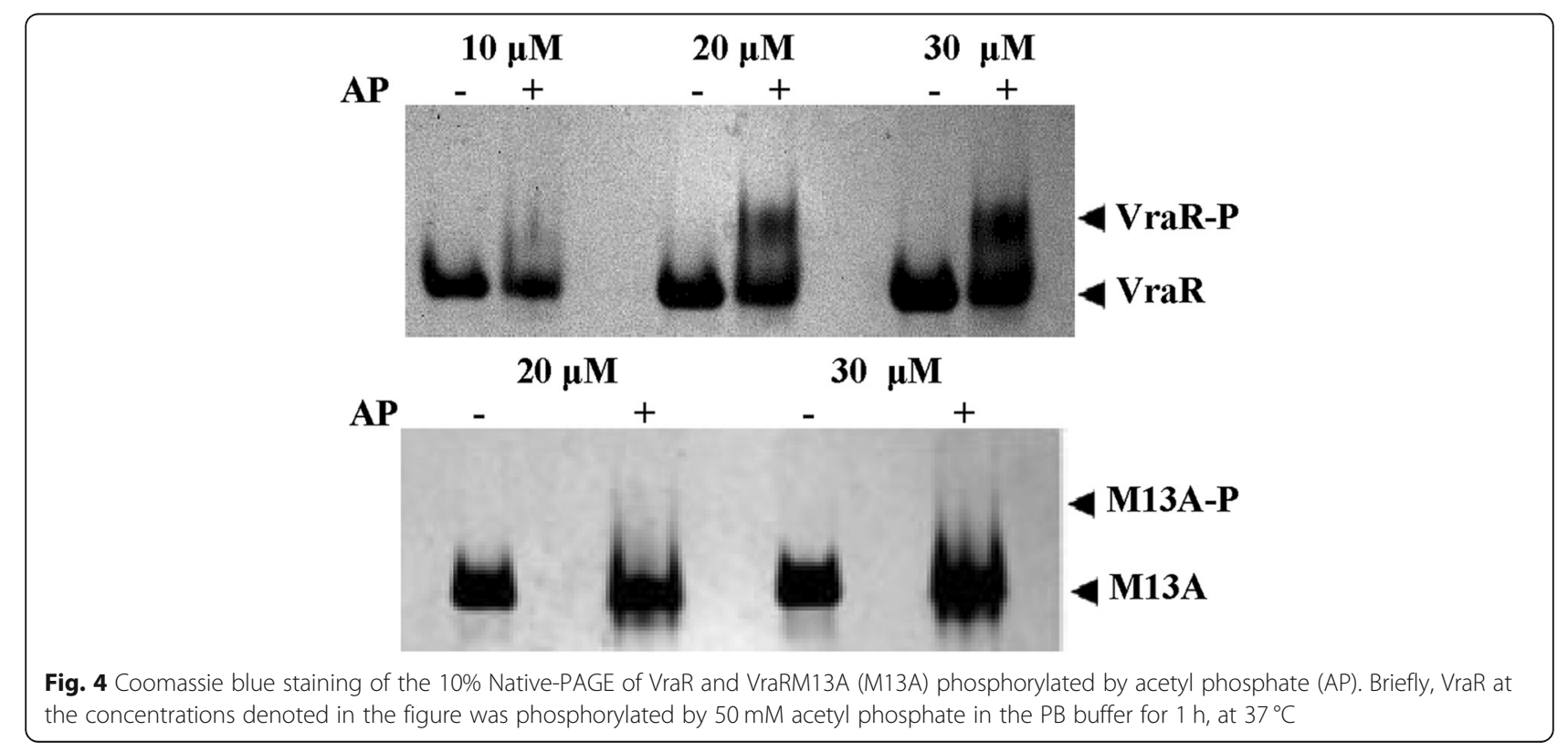




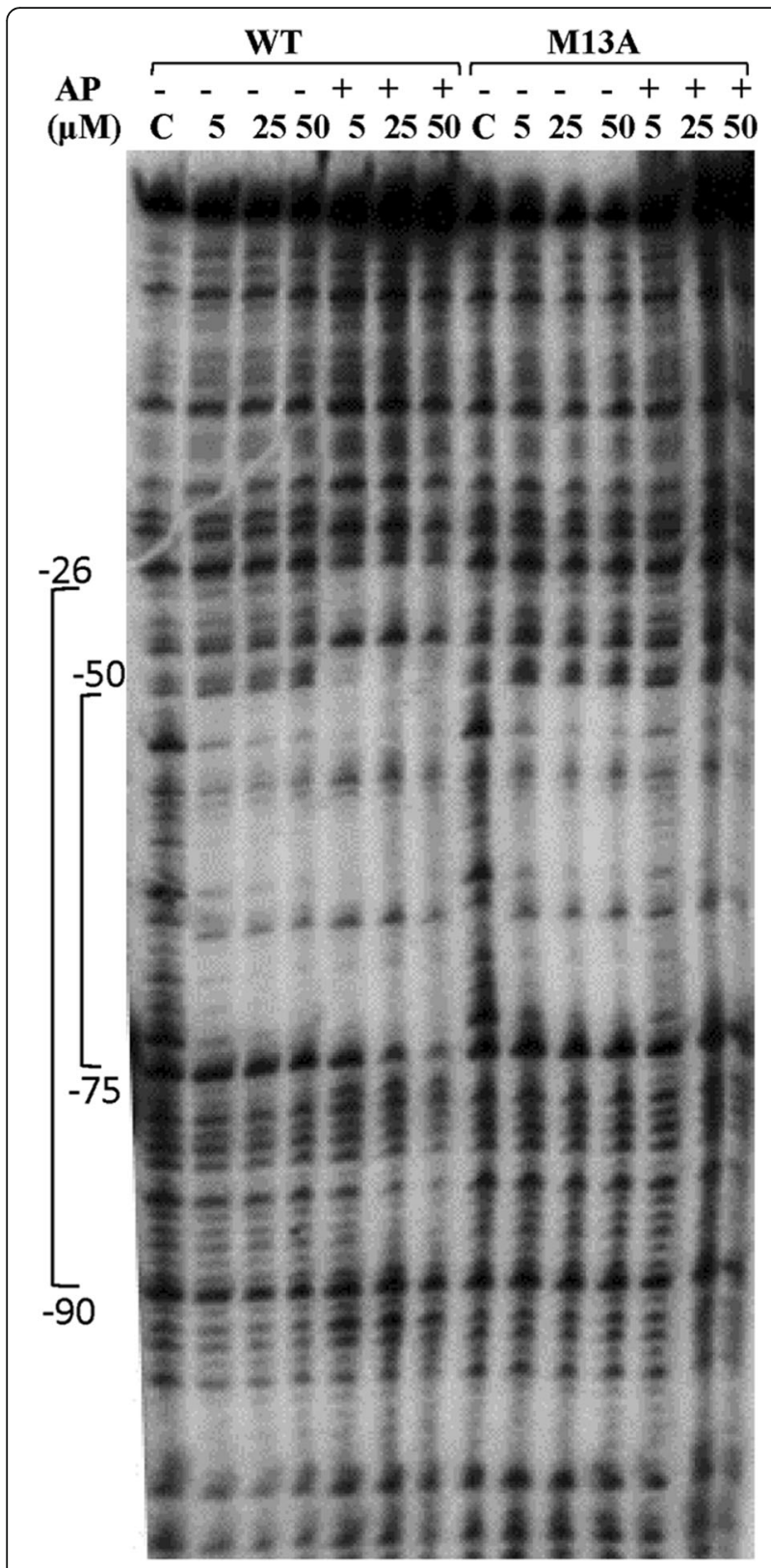

Fig. 5 DNase I footprinting experiment. The top strand of $P_{\text {vrasR }}$ was labelled with ${ }^{32} \mathrm{P}$ at the $5^{\prime}$-end, and incubated with VraR, VraR-P, VraMet13Ala (M13A), and VraRM13A subjected to phosphorylation with acetyl phosphate. The sample were each protein was absent from the reaction mixture is denoted by $C$

expression levels of $v r a R$ in the absence and presence of oxacillin using RT-qPCR (data not shown).

In the current study, we selected a few genes from the $v r a R$ regulon to assess the effect of the Met to Ala substitution into the transcriptional activity of VraR. These genes were fmt $A, \operatorname{sgt} B$ and $p b p B$ [6]. Expressions of these genes in the absence of oxacillin were compared to their respective gene expressions

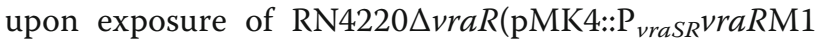

3A) to sub-inhibitory concentration of oxacillin, for 30 min (data not shown). In all the cases, the complementation of RN4220 $\Delta v r a R$ with vraRM13A variant failed to increase gene expression of $v r a R, f m t A, \operatorname{sgt} B$ and $p b p B$ in response to oxacillin. The lack of upregulation of the above genes in the presence of oxacillin is very likely due to the failure of $v \mathrm{raRM} 13 \mathrm{~A}$ to be induced by oxacillin in the RN4220 $v$ vraR(pMK4:: $\mathrm{P}_{\text {vrasR }}$ vraRM13A) strain.

\section{Discussion}

Substitution of a single residue in VraR, Met13 to Ala, led to the inability of VraR to undergo quantitative phosphorylation by small molecule donors such as acetyl phosphate and to dimerize in vitro. In vivo, complementation of the RN4220 $v$ raR strain with vraRM13A did not lead to a response to oxacillin-induced stress. We had earlier suggested that the dimerization domain in VraR is located at the regulatory domain [14]. The X-ray crystal structure of the VraR dimer showed that the dimerization interface in the active VraR species $\left(\mathrm{BeF}^{3-}-\mathrm{VraR}\right.$ bound species) is located at the regulator domain of VraR [16]. Peculiarly, at the center of this dimerization interface was the side chain of Met13, sitting on the $\alpha 1$ helix and snugly fitted into a hydrophobic pocket formed on the opposing molecule of VraR in the dimer [16]. In this study, we show that substitution of Met13 with Ala does not have measurable effects on the overall VraR structural integrity as assessed by CD. Thus, any impact on the activity of VraMet13Ala was attributed to the lack of the methionine-13 side chain.

Autophosphorylation of VraRM13A by a small molecule phosphodonor such as acetyl phosphate was about 7-fold less compared to the wild-type protein. We attributed this outcome to the inability of VraRM13A to dimerize in the absence of the methionine sidechain. Dimerization is considered to be a process that drives forward phosphorylation of RR [26]. The aspartyl phosphate species carry a high negative free energy and dimerization can channel that energy in the form of conformational changes in the protein. These conformational changes, which mark activation of RR, facilitate binding of RR to itself (oligomerization) and/or the target DNA sequence or other proteins [26]. So if dimerization is impeded, the phosphorylation of RR will also be affected (Fig. 6). This explains the slower phosphorylation rate of VraM13A and highlights the significance of the Met-13 residue in dimerization of VraR.

Phosphorylation of VraR is required for upregulation of its own operon, the vraSR operon [15, 17]. We had shown earlier that phosphorylation-induced dimerization of VraR is required to bind to a lesser conserved DNAbinding site on the vraSR promoter, namely the R2 site (Fig. 1b); while a conserved DNA-binding site, namely the R1 site, in the same promoter, can recruit 


\section{VraR}

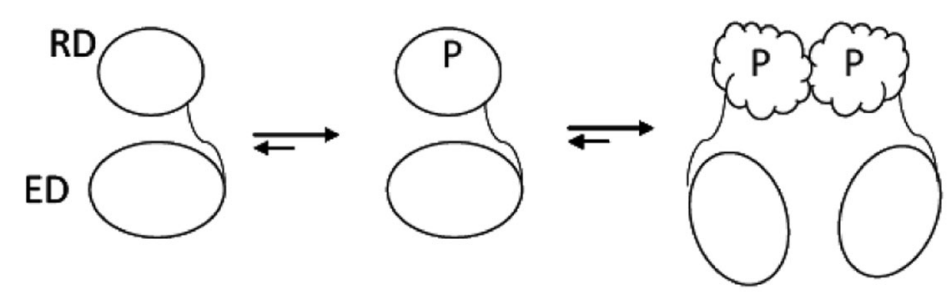

VraRM13A

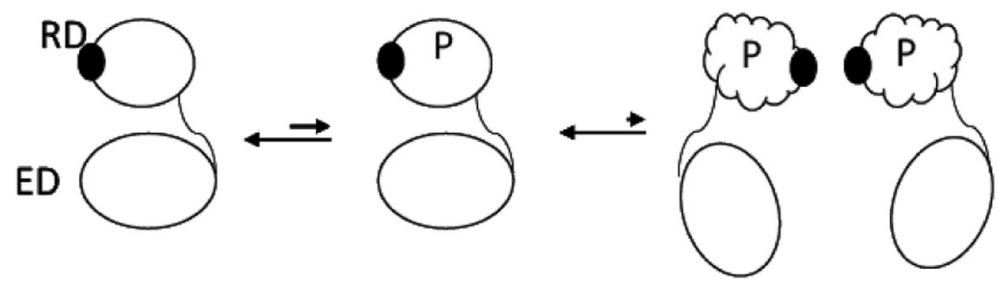

Fig. 6 The schematic view of the structural rearrangements that take place upon VraR-P dimerization that lead to the activation of the protein

the unphosphorylated VraR protein (Fig. 1b). In the case of VraRM13A, the DNase I footprinting experiments showed that subjection of this variant protein to phosphorylation did not lead to binding to the R2 site even at protein concentrations as high as $50 \mu \mathrm{M}$. However, the conserved DNA-binding site, the R1 site, was occupied by VraRM13A. This result confirms our earlier work that dimerization of $\mathrm{VraR}$ is required for recognition of a DNA-binding site that is less conserved [17]. The significance of dimerization in gene activation by VraR was corroborated by the RT-qPCR experiments. Indeed, the wild-type $v \mathrm{raR}$ gene was able to complement the RN4220 $\Delta v r a R$ strain, and mediate the vraR regulon in the presence of oxacillin, as indicated by the increased in the expression levels of the $f m t A, \operatorname{sgtB}$ and $p b p B$ genes. However, complementation of the RN4220 $\Delta v r a R$ strain with $\operatorname{vraRM13A}$ failed to mediate the $\operatorname{vraR}$ regulon in the presence of oxacillin, as indicated by the lack thereof of upregulation of the above genes. This observation is very likely due to the lack of upregulation of the vraSR operon in the presence of oxacillin. VraR is known to regulate its own operon, hence if VraRM13A is not able to bind to its own promoter optimally it will not lead to higher expression levels of $v r a R$ in the presence of stress, and subsequently VraR cannot regulate its target genes.

\section{Conclusions}

The impacts of substitution of Met13 with Ala on the phosphorylation rate, dimerization and gene activation by VraR demonstrates the significance of this residue in driving the phosphorylation-induced activation of
VraR, and hence cell wall stress response in $S$. aureus. As such, targeting the dimerization interface in VraR, and possibly in other response regulators of the NarL/FixJ family, through small molecules is a strategy that can efficiently disrupt the signal transduction mechanism of bacterial response to their respective stimuli. In addition, due to their conservative nature, inhibition of RR offers a global strategy in targeting a wide range of pathogens. Furthermore, RRs offer a unique and a direct site of inhibition in TCSs; in the past, inhibition of HK did not lead to inactivation of $R R$ due to the ability of RR to cross-talk with other phosphate-donors in the cell and by-pass the histidine kinase [4].

\section{Methods}

Chemicals, growth media, and antibiotics were purchased from Thermo-Fisher (Whitby, Canada) or Sigma (Oakville, Canada), unless otherwise stated. Escherichia coli strains, such as NovaBlue and BL21(DE3), and other expression plasmids were purchased from EMD4 Biosciences (New Jersey, USA). All the primers were purchased from Sigma (Oakville, Canada). Chromatography columns and media were bought from GE Healthcare (Mississauga, ON, CA). Radioactive $\left[\gamma_{-}{ }^{32} \mathrm{P}\right]$-ATP was purchased from Perkin Elmer (Life and Analytical Sciences, Waltham, MA, USA).

\section{Generation of the vraRM13A variant, production and purification of the VraRM13A protein}

The vraRM13A variant was generated through site directed mutagenesis using the QuikChange Site-Directed Mutagenesis kit (Agilent). The nucleic acid sequences of 
the mutagenic primers used in these experiments were as follows: Dir: 5'-GTGGATGATCATGAAGCGGTAC GTAT AG, Rev.: 5'-CTATACGTACCGCTTCATGATCATCCAC. The pET26b::vraR vector [14] was amplified using the above mutagenic primer pair as suggested by the vendor. The resulting amplicon was subjected to digestion by $\mathrm{Dpn} I$ and then used to transform $E$. coli NovaBlue. Mutation was confirmed by DNA sequencing at the Centre for Applied genomics (TCAG) facilities (Sick Kid's Hospital). The mutated pET26b::vraRM13A vector was introduced into the expression host $E$. coli BL21(DE3). The induction, isolation and purification of VraRM13A variant were carried out similarly to that of the wild-type protein, and as described by [14].

\section{Circular dichroism (CD) spectroscopy and thermal melting of VraRM13A}

The CD spectrum of the target protein was carried out by preparing a protein solution of $10 \mu \mathrm{M}$ in $20 \mathrm{mM}$ Tris, $\mathrm{pH} 7.0$ buffer, and supplemented with $5 \mathrm{mM} \mathrm{MgCl} 2$. The CD spectrum was recorded from 200 to $260 \mathrm{~nm}$ in a Jasco J-810 instrument $(0.1 \mathrm{~cm}$ path length cuvette). To investigate the effect of the mutation on the overall structure of the protein, the thermal melting of the protein was carried out by monitoring the $\mathrm{CD}$ signal at 222 nm from $20^{\circ} \mathrm{C}$ to $100^{\circ} \mathrm{C}$ in a Jasco J-810 instrument.

\section{Phosphorylation of VraR by lithium potassium acetyl phosphate}

Phosphorylation of VraR, or VraM13A variant $(10 \mu \mathrm{M}$ or $20 \mu \mathrm{M}$ ), was carried out with $50 \mathrm{mM}$ acetyl phosphate in the phosphorylation buffer (1X PB: $50 \mathrm{mM}$ Tris, pH 7.4 buffer, $50 \mathrm{mM} \mathrm{KCl,} 20 \mathrm{mM} \mathrm{MgCl} 2$ ). The reaction mixtures were incubated for up to $1 \mathrm{~h}$ at $37^{\circ} \mathrm{C}$. The extent of protein phosphorylation was evaluated by Phos-tag $^{\text {Tw }} 12.5 \%$ SDS polyacrylamide gel electrophoresis (PAGE) [27].

\section{Examination of the oligomerization state of VraR and VraM13A by native-PAGE}

Dimerization of VraR and its variant upon phosphorylation was examined by native-PAGE. Briefly, the protein at concentrations $10 \mu \mathrm{M}, 20 \mu \mathrm{M}$, and $30 \mu \mathrm{M}$ was phosphorylated as described above and samples were resolved into a $10 \%$ native-PAGE at $4{ }^{\circ} \mathrm{C}$.

\section{DNase I footprinting assay}

To perform this assay the region -121 to +26 of the vraSR promoter $\left(\mathrm{P}_{\text {vraSR }}\right)$ was amplified by PCR using a ${ }^{32} \mathrm{P}-5^{\prime}$-end direct primer Dir: 5'-ACGAAGCTTGG TCCGATTTTAACGAC AAAAATTG-3' and a reverse primer Rev: 5'-TGAAATGACGCATTGATTGTGTTC3' [15]. The amplicon (2 ng) was incubated with VraR, phosphorylated VraR (VraR-P), VraRM13A and VraRM 13A subjected to phosphorylation (VraRM13A/P) at different concentrations $(0,2,5,25$, and $50 \mu \mathrm{M})$ in the binding buffer $(10 \mathrm{mM}$ Tris, pH 7.5 buffer, $50 \mathrm{mM} \mathrm{KCL}, 1 \mathrm{mM}$ DTT) supplemented with $10 \mathrm{mM} \mathrm{MgCl} 2,50 \%$ glycerol and $20 \mathrm{ng} / \mu \mathrm{l}$ Herring sperm DNA. Each binding reaction was subjected to DNase I for 2 min to digest the DNA and then the DNase I stop solution (1\% SDS, $0.2 \mathrm{M} \mathrm{NaCl}, 20$ mM EDTA, pH 8.0) to stop the reaction. Samples were resolved by an $8 \%$ polyacrylamide gel containing urea, and the DNA bands were visualized using a Typhoon Trio ${ }^{+}$ Variable Mode Imager (GE HealthCare).

\section{Construction of the complementing vector, pMK4:: PrasR $_{\text {VraR }}$}

In these experiments, the vraSR promoter region from -121 to $+150\left(\mathrm{P}_{\text {vraSR }}\right)$ was fused to the vraR gene (PvraSR::vraR) and the entire sequence was cloned into the pMK4 shuttle vector in order to complement the $S$. aureus $\Delta v \mathrm{raR}$ strain and assess the effect of the M13A substitution into the VraR activity in vivo, by RT-qPCR. Briefly, $P_{\text {vraSR }}$ was amplified using the primer pair Dir: 5'AGGAATTCGGTCCGATTTTAACGACAAAAATTG and Rev.: 5'CGGGATCCAC GTTCAACATAGTTCATAAC (the underlined regions represent the sequences of the restriction enzyme sites, EcoRI and BamHI respectively) and the $\operatorname{vraR}$ gene was amplified using the primer pair Dir: 5'CGGGATCCATGACGATTAAAGTATTGTTTG and Rev.: 5'GCGTCGACCTAT TGAA TTAAATTATGTTG (the underlined regions represent the sequences of the restriction enzyme sites, $\mathrm{BamHI}$ and Sal $I$ respectively). The $\mathrm{P}_{v r a S R}: v \operatorname{vraR}$ construct was ligated into the pMK4 vector at the EcoRI and Sal $I$ restriction sites. The sequence of the construct was confirmed by DNA sequencing. The pMK4:: $\mathrm{P}_{\text {vrasR }}$ vraR plasmid was introduced to $S$. aureus RN4220 $\Delta$ vraR competent cells by electroporation $(2 \mathrm{kV}, 2.5 \mathrm{~ms})$ using Micropulser (Bio-Rad) and were grown on TSB agar supplemented by $10 \mu \mathrm{g} / \mathrm{ml}$ chloramphenicol. Introduction of the mutation on the vraR gene at the pMK4:: $\mathrm{P}_{\text {vraSR }} v$ raR plasmid was carried out by site-directed mutagenesis as outlined above.

\section{RT-qPCR to investigate expression of the vraR regulon} genes in the RN4220 $\Delta v r a R$ strain complemented with vraRM13A

An overnight seed culture of one of the RN4220 strains was prepared in TSB media supplemented by $10 \mu \mathrm{g} / \mathrm{ml}$ chloramphenicol. An aliquot of $160 \mu \mathrm{l}$ of overnight seed culture were used to inoculate $16 \mathrm{ml}$ TSB medium supplemented with $10 \mu \mathrm{g} / \mathrm{ml}$ chloramphenicol. The subsequent culture was incubated at $37^{\circ} \mathrm{C}(200 \mathrm{rpm})$ up to an optical density at $600 \mathrm{~nm}\left(\mathrm{OD}_{600}\right)$ of 0.4 . The culture 
Table 1 The DNA sequence of the primers used in the RT-qPCR studies

\begin{tabular}{ll}
\hline Primer name & Primer Sequence 5 $^{\prime}>$ 3' $^{\prime}$ \\
\hline vraRDir & TTGAACCGGAAGTTTAGTG \\
sgtBDir & TCCATTCTCGTTCTGTAAGC \\
sgtBRev & CCTTCAAATCGAATCCATGA \\
fmtADir & TCAGCTGATAACATGCCAGAG \\
fmtARev & TGGTACGAAAAAGTATCCAGATG \\
pbp2Dir & CCAAAGAATCCCCCGTTAAG \\
pbp2Rev & GAACATGGCGCACTTGATA \\
\hline & GAGGCACCTTCAGAACCAAA \\
\hline
\end{tabular}

was split into two $5 \mathrm{ml}$ aliquots and one of them was treated with $10 \mu \mathrm{g} / \mathrm{ml}$ oxacillin which was incubated along with the control sample, namely the non-oxacillin treated sample, at $37^{\circ} \mathrm{C}$ for $30 \mathrm{~min}$. An aliquot of $1 \mathrm{ml}$ growth culture was used to isolate RNA using the RNeasy Mini kit (Qiagen) as per vendor's instructions.

High Capacity RNA-to-cDNA kit (Life Technologies) was used to synthesize cDNA from $500 \mathrm{ng}$ of DNase I treated RNA. The $16 \mathrm{~s}$ RNA gene was used as an internal control using designed primers: Dir5'GCTAAGTGTTAGGGGGTTTCC and Rev-5'TTCA ACCTTGCGGTCGTACT. The $20 \mu \mathrm{l}$ reaction mixtures consisted of $25 \mathrm{ng}$ of cDNA, $0.25 \mu \mathrm{M}$ of each primer (accordingly designed to target specific gene, Table 1), and $10 \mu \mathrm{l}$ of SYBRE SELECT Master Mix (Life Technologies). The Rotor-gene Q qRT-PCR cycler (Qiagen) was used to amplify the cDNA. The PCR conditions were as follows: First hold: $2 \mathrm{~min}$ at $50^{\circ} \mathrm{C}$, second hold: 10 min for $95^{\circ} \mathrm{C}, 40$ cycles of $95^{\circ} \mathrm{C}$ for $15 \mathrm{~s}, 60^{\circ} \mathrm{C}$ for $30 \mathrm{~s}$, and $72{ }^{\circ} \mathrm{C}$ for $30 \mathrm{~min}$; and $72^{\circ} \mathrm{C}$ for $10 \mathrm{~min}$ as a final extension step. The sequences of the primers that were used to probe the expression of genes such as $v \mathrm{raR}, \mathrm{fmt} A$, $s g t B$ and $p b p B$ are provided in Table 1.

\section{Additional files}

Additional file 1: CD spectra. CD spectra of VraR and VraRM13A, and their respective thermal melting graphs. (PDF $57 \mathrm{~kb}$ )

Additional file 2: DNase I footprinting. Binding isotherms extracted from the DNase I footprinting experiments. (PDF $45 \mathrm{~kb}$ )

\section{Abbreviations}

ATP: Adenosine triphosphate; CD: Circular dichroism; EMSA: Electromobility shift assay; PAGE: Polyacrylamide gel electrophoresis; PCR: Polymerase chain reaction; RT: Reverse transcription; SDS: Sodium dodecyl sulphate; VraR: Vancomycin-resistance-associated response regulator protein
}

\section{Authors' contributions}

DGK designed the project, analyzed and interpreted the data, and wrote the manuscript; GT carried out the experiments, analyzed the data and prepared the manuscript. All the authors have read and approved the manuscript.

\section{Funding}

Natural Sciences and Engineering Research Council of Canada is responsible for funding the project; Grant ID: RGPIN-05829-2015. This grant funded the design and execution of the project, the analysis and interpretation of the data, and the writing of the manuscript.

\section{Availability of data and materials}

The datasets supporting the conclusions of this article are included within the article and/or additional supporting files, with the exception of the RTqPCR data. The RT-qPCR data are available from the corresponding author on reasonable request.

\section{Ethics approval and consent to participate}

Not applicable.

\section{Consent for publication}

Not applicable.

\section{Competing interests}

The authors declare that they have no competing interests.

Received: 2 May 2019 Accepted: 24 June 2019

Published online: 05 July 2019

\section{References}

1. Hoch JAST. In: Hoch JAST, editor. Two-omponent signal transduction. Washington DC: American Society for Microbiology; 1995.

2. Stock AM, Robinson VL, Goudreau PN. Two-component signal transduction. Annu Rev Biochem. 2000;69:183-215.

3. Jordan S, Hutchings Ml, Mascher T. Cell envelope stress response in Grampositive bacteria. FEMS Microbiol Rev. 2008;32(1):107-46.

4. Stephenson K, Hoch JA. Two-component and phosphorelay signaltransduction systems as therapeutic targets. Curr Opin Pharmacol. 2002; 2(5):507-12.

5. Gao R, Mack TR, Stock AM. Bacterial response regulators: versatile regulatory strategies from common domains. Trends Biochem Sci. 2007;32(5):225-34.

6. Kuroda M, Kuroda H, Oshima T, Takeuchi F, Mori H, Hiramatsu K. Twocomponent system VraSR positively modulates the regulation of cellwall biosynthesis pathway in Staphylococcus aureus. Mol Microbiol. 2003;49(3):807-21

7. Boyle-Vavra S, Yin S, Daum RS. The VraS/VraR two-component regulatory system required for oxacillin resistance in community-acquired methicillinresistant Staphylococcus aureus. FEMS Microbiol Lett. 2006;262(2):163-71.

8. McCallum N, Meier PS, Heusser R, Berger-Bachi B. Mutational analyses of open reading frames within the vraSR operon and their roles in the cell wall stress response of Staphylococcus aureus. Antimicrob Agents Chemother. 2011;55(4):1391-402.

9. Kato Y, Suzuki T, Ida T, Maebashi K, Sakurai M, Shiotani J, et al. Microbiological and clinical study of methicillin-resistant Staphylococcus aureus (MRSA) carrying VraS mutation: changes in susceptibility to glycopeptides and clinical significance. Int J Antimicrob Agents. 2008; 31(1):64-70.

10. Baek JY, Chung DR, Ko KS, Kim SH, Yang SJ, Kang Cl, et al. Genetic alterations responsible for reduced susceptibility to vancomycin in community-associated MRSA strains of ST72. J Antimicrob Chemother. 2017; 72(9):2454-60.

11. Iwata Y, Satou K, Tsuzuku H, Furuichi K, Senda Y, Sakai-Takemori Y, et al. Down-regulation of the two-component system and cell-wall biosynthesisrelated genes was associated with the reversion to daptomycin susceptibility in daptomycin non-susceptible methicillin-resistant Staphylococcus aureus. Eur J Clin Microbiol Infect Dis. 2017:36(10):1839-45.

12. Dengler $V$, Meier PS, Heusser R, Berger-Bachi B, McCallum N. Induction kinetics of the Staphylococcus aureus cell wall stress stimulon in response to different cell wall active antibiotics. BMC Microbiol. 2011;11:16. 
13. Gardete S, Ludovice AM, Sobral RG, Filipe SR, de Lencastre H, Tomasz A. Role of murE in the expression of beta-lactam antibiotic resistance in Staphylococcus aureus. J Bacteriol. 2004;186(6):1705-13.

14. Belcheva A, Golemi-Kotra D. A close-up view of the VraSR two-component system. A mediator of Staphylococcus aureus response to cell wall damage. J Biol Chem. 2008;283(18):12354-64.

15. Belcheva A, Verma V, Golemi-Kotra D. DNA-binding activity of the vancomycin resistance associated regulator protein $\mathrm{VraR}$ and the role of phosphorylation in transcriptional regulation of the vraSR operon. Biochemistry. 2009;48(24):5592-601.

16. Leonard PG, Golemi-Kotra D, Stock AM. Phosphorylation-dependent conformational changes and domain rearrangements in Staphylococcus aureus VraR activation. Proc Natl Acad Sci U S A. 2013;110(21):8525-30.

17. Belcheva A, Verma V, Korenevsky A, Fridman M, Kumar K, Golemi-Kotra D. Roles of DNA sequence and sigma a factor in transcription of the vraSR operon. J Bacteriol. 2012;194(1):61-71.

18. Liu YH, Belcheva A, Konermann L, Golemi-Kotra D. Phosphorylation-induced activation of the response regulator VraR from Staphylococcus aureus: insights from hydrogen exchange mass spectrometry. J Mol Biol. 2009; 391(1):149-63.

19. Webber CA, Kadner RJ. Involvement of the amino-terminal phosphorylation module of UhpA in activation of uhpT transcription in Escherichia coli. Mol Microbiol. 1997;24(5):1039-48.

20. Schnell R, Agren D, Schneider G. 1.9 A structure of the signal receiver domain of the putative response regulator NarL from mycobacterium tuberculosis. Acta Crystallogr Sect F Struct Biol Cryst Commun. 2008;64(Pt 12):1096-100

21. Trajtenberg F, Albanesi D, Ruetalo N, Botti H, Mechaly AE, Nieves M, et al. Allosteric activation of bacterial response regulators: the role of the cognate histidine kinase beyond phosphorylation. MBio. 2014;5(6):e02105.

22. Davlieva M, Tovar-Yanez A, DeBruler K, Leonard PG, Zianni MR, Arias CA, et al. An adaptive mutation in enterococcus faecium LiaR associated with antimicrobial peptide resistance mimics phosphorylation and stabilizes LiaR in an activated state. J Mol Biol. 2016;428(22):4503-19.

23. Toro-Roman A, Mack TR, Stock AM. Structural analysis and solution studies of the activated regulatory domain of the response regulator ArcA: a symmetric dimer mediated by the alpha4-beta5-alpha5 face. J Mol Biol. 2005;349(1):11-26.

24. Chakrabartty A, Kortemme T, Baldwin RL. Helix propensities of the amino acids measured in alanine-based peptides without helix-stabilizing sidechain interactions. Protein Sci. 1994;3(5):843-52.

25. Fridman M, Williams GD, Muzamal U, Hunter H, Siu KW, Golemi-Kotra D. Two unique phosphorylation-driven signaling pathways crosstalk in Staphylococcus aureus to modulate the cell-wall charge: Stk1/Stp1 meets GraSR. Biochemistry. 2013;52(45):7975-86.

26. Stock J, Da Re S. Signal transduction: response regulators on and off. Curr Biol. 2000;10(11):R420-4.

27. Kinoshita E, Kinoshita-Kikuta E, Takiyama K, Koike T. Phosphate-binding tag, a new tool to visualize phosphorylated proteins. Mol Cell Proteomics. 2006; 5(4):749-57.

\section{Publisher's Note}

Springer Nature remains neutral with regard to jurisdictional claims in published maps and institutional affiliations.

Ready to submit your research? Choose BMC and benefit from:

- fast, convenient online submission

- thorough peer review by experienced researchers in your field

- rapid publication on acceptance

- support for research data, including large and complex data types

- gold Open Access which fosters wider collaboration and increased citations

- maximum visibility for your research: over $100 \mathrm{M}$ website views per year

At $\mathrm{BMC}$, research is always in progress.

Learn more biomedcentral.com/submissions 